\title{
Effect of the Shadings Pattern and Greenery Strategies on the Outdoor Thermal Comfort
}

\author{
Suaad Ridha, Stéphane Ginestet, and Sylvie Lorente
}

\begin{abstract}
The outdoor thermal comfort is influenced by the perception and satisfaction of the pedestrians, especially in hot and arid climates. Accordingly, the researchers look for the appropriate methods to reduce the Urban Heat Island and thus to enhance the outdoor thermal comfort level of pedestrians. However, there is limited research conducted on the outdoor thermal comfort in hot and arid climate. This work is an investigation study conducted in an urban area (Haifa Street) in Baghdad city, characterized by an arid climate with very high temperatures in summer season reaching $50^{\circ} \mathrm{C}$. This study focuses on investigating possible mitigation strategies to ensure how we could improve the thermal comfort at pedestrian level for an urban area with intricate Western design (high-rise buildings, a large spacing between the buildings, asymmetrical canyon geometry, and lack of vegetation). We created four different scenarios to assess the role of vegetation elements such as trees, grass, and different shading patterns. The evaluation was performed in the hottest day in summer. For each scenario, the mean radiant temperature, specific humidity, air temperature, and wind speed distributions have been analyzed using ENVI-met software. Thermal comfort is assessed using the PET thermal index (Physiological Equivalent Temperature) and Predicted Mean Vote (PMV). The results reveal that the PET index can be reduced to $10.4^{\circ} \mathrm{C}$ the temperature can be decreased of about $2.4^{\circ} \mathrm{C}$ and PMV to 3 . The study shows how the urban factors such as the aspect ratio, vegetation cover, shadings, and geometry of the canyon are crucial elements that urban planners and municipalities have to take into account, especially for new urban developments.
\end{abstract}

Index Terms-Outdoor thermal comfort, Pedestrians, ENVI-met, PET, PMV, Urban Heat Island.

\section{INTRODUCTION}

The studies on the Mitigation Urban Heat Island and the outdoor thermal comfort are almost non-existent for Baghdad city. Baghdad has a complex urban fabric with modern design constructions buildings, traditional and heritage houses. The climate in summer is hot, and summer months are considered the longest season with nearly 7 months in the year. There are many studies on the importance of the mitigation of Urban Heat Island for improving the climate and the environmental factors in the neighbouring urban areas of Iraq (Fig. 1). In a study on the role of the greenery strategy [1], the research results revealed that the green roofs were proved to perform poorly

Manuscript received November 4, 2016; revised May 1, 2017.

Suaad Ridha is with LMDC, Université de Toulouse, INSAT, UPS, France and Al-Mustansiriyah University, College of Engineering, Baghdad, Iraq (e-mail: suaad.ridha@gmail.com).

Stéphane Ginestet and Sylvie Lorente are with LMDC, Université de Toulouse, INSAT, UPS, France (e-mail: sginestet@insa-toulouse.fr, lorente@insa-toulouse.fr). in reducing the surface temperatures in urban areas; this is because the cooling effects of green roofs reduce by distance and therefore this effect is negligible on the overall temperature reduction in urban areas. Also, regarding the composition of greenery, trees have the best contribution in the reduction of surface temperatures in the urban areas of Dubai [1].

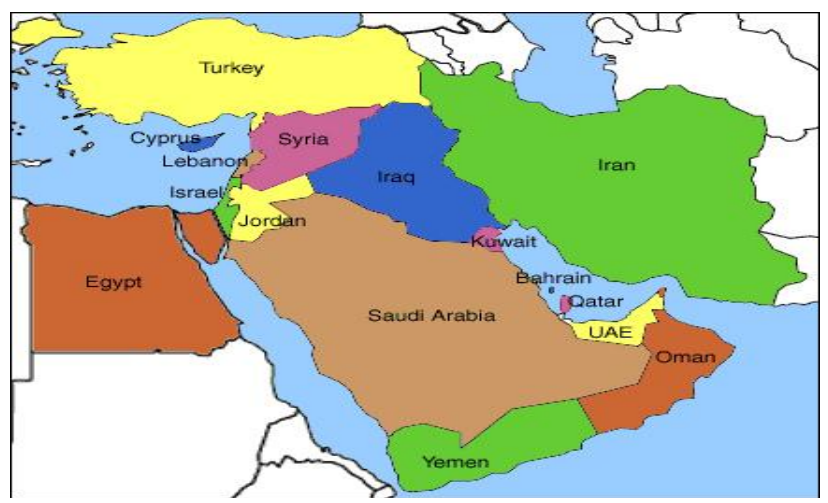

Fig. 1. Location of Iraq and the neighbouring countries.

Regarding the investigation study conducted in Iran (Tehran city) on the strategies to reduce the impact of Urban Heat Island on the human health [2], the results showed that the amount of vegetation placed on a building and its position (roofs, walls or both) is a more dominant factor than the orientation of the urban canyon. The canyon geometry with green roofs and walls that had a low thermal impact could play a more important role than the street orientation. Also, the study revealed that the heat sensation zones "hot" and "warm" are not achieved when urban roofs and walls are covered with vegetation, leading to more pleasant and comfort environments for the city residents. An investigation study was conducted of the warm core of Urban Heat Island in the highland zone of Muscat, Oman [3]. The valley is surrounded by mountains formed of dark colored rocks that can absorb the short wave radiation and contribute to the existence of the warmth in the core of the urban area. The study emphasized the importance of the nature of rural baseline when assessing the urban effect on an urban area climate. A study was conducted in Bahrain City [4] to analyze the impact of the urbanization on the thermal behaviour of newly built environments. The results revealed that the recent process of the urbanization leads to an increase in the urban temperature by $2-5^{\circ} \mathrm{C}$. The increase in temperature is enhanced by the urban activity such as ongoing construction processes, shrinkage of green areas and the sea reclamation. Several studies indicate how the green effects have a crucial role in the process of sustainable cooling of the urban planning and in saving energy and 
improving human thermal comfort. A study characterized how the presence of vegetation within the urban environment is an essential element for improving the quality of urban spaces [5]. The cooling effect of the green parks is remarkable not only locally in vegetated areas, but it can also be extended to the surrounding built environment [6].

The history of thermal comfort came from the military scope, from the necessity to ensure that the military could continue the work on the ship and airplanes even in the environment with high temperatures [7]. Recently, researchers began to take an interest in the effect of the outdoor thermal comfort, whereas most of them regarded thermal comfort as mainly concerning the interior space. The study of thermal comfort is to be conducted by considering various physical, physiological and psychological aspects, accounting for the interrelationships between the thermal conditions of the environment, physiological responses and psychological phenomena. Many factors effect on the thermal comfort, these factors could classify into three categories [8]:

1) Climatic factors such as the effect of air temperature, relative humidity, the radiation, and the velocity.

2) Personal factors which belong to the metabolism and the clothing.

3) Contributing factors like the influence of the acclimation with the environment, age.

\section{THERMAL COMFORT INDICES}

Thermal comfort had been discussed since 1930 [9]. There are two approaches to thermal comfort: the steady state model and the adaptive model. The adaptive model is based on the theory of the human body adapting to the outdoor and indoor climate [9]. Human thermal comfort can be defined as the condition of the mind in which satisfaction as a thermal comfort. Fabbri [10] defined the comfort as the result of the interaction of many parameters of physical, physiological, psychological, social and culture rights. Thermal comfort depends on the architecture, clothing, the habits of eating and the climate. The discomfort is caused by a vertical air temperature difference between the feet and the head, by an asymmetric radiant field, by the local convection cooling or by contact with a hot or cold floor [11]. The mean radiant temperature (Tmrt) indicates the level of radiant temperature received by the human body (Fig. 2). The radiation includes all the radiative fluxes (direct, diffuse, reflected solar radiation and long-wave emissions from the surfaces [12]. Mean Radiant Temperature is considered as the most important factor affecting the human thermal comfort in an outdoor urban area [13]. The value of Tmrt is the sum of all short-wave and long-wave radiation fluxes absorbed by the human body that affects its energy balance and human thermal comfort [14]. Peng et al., [15] confirmed that the Mean Radiant Temperature is a more accurate indicator than air temperature to evaluate the thermal comfort. Thorsson et al., [16] came to the same conclusion, stating that the Mean Radiant Temperature is the most important meteorological parameter governing the human energy balance and the thermal comfort.

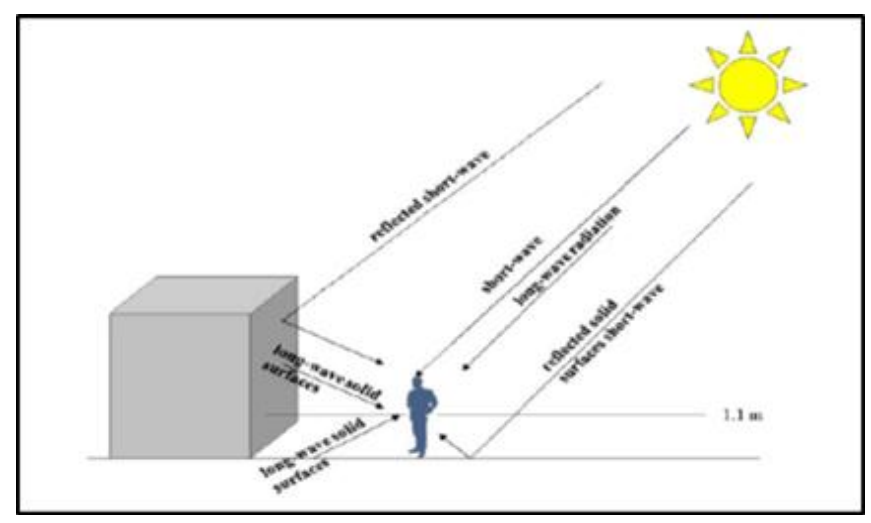

Fig. 2. The radiation flux densities important for the determination of the mean radiant temperature [17].

The increase in incoming radiation leads to a high capacity of heat storage which contributes to intensifying the Urban Heat Island. The Physiological Equivalent Temperature (PET) is considered to be a good understanding of the effect of radiation and wind velocity on the thermal comfort and the heat storage in an urban area [18]. Note that the Mean Radiant Temperature is considered to have the strongest influence on the physiologically significant thermal indexes like the Physiological Equivalent Temperature (PET) or the Predicted Mean Vote (PMV) which are derived from the models of human energy balance. According to Ali-Toudert and Mayer [19], many studies showed that the outdoor thermal comfort is strongly dependent on the short wave and long wave radiation fluxes surrounding human activity. They confirmed that shading plays an important role in the strategy for heat mitigation in summer, together with the orientation of the street. The strategies for mitigating the Urban Heat Island and improving human thermal comfort do not always match. The Urban Heat Island occurs in nocturnal time, while the outdoor human thermal comfort deals with daytime (Fig. 3). The differences happen mainly in the way mitigation strategies address the high exterior mass, and the high heat capacity of urban materials [20].

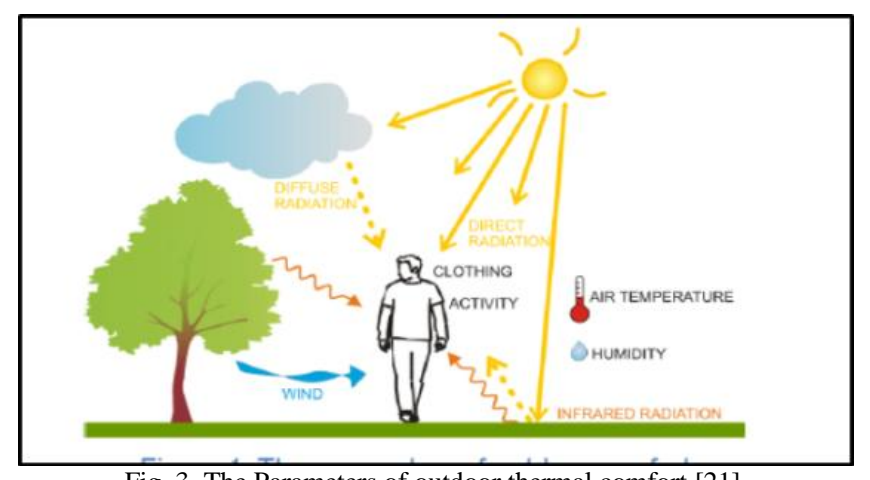

Fig. 3. The Parameters of outdoor thermal comfort [21]

Recent investigations indicated that (PET) is the index that could be used to assess the thermal comfort conditions of outdoor environments rather than the indoor based thermal indices. Makaremi et al., [22] concluded from their results that the human thermal comfort in outdoor spaces of a hot and humid climate of Malaysia could be integrated into the design guidelines to enhance the outdoor human comfort in the tropical areas. (PET) index utilized to assess 
the thermal comfort conditions (Table I).

TABLE I: CLASSIFICATION OF PET VALUES IN TERMS OF THE THERMAL PERCEPTION AND HEAT STRESS [23]

\begin{tabular}{|c|c|c|}
\hline PET & $\begin{array}{l}\text { Thermal } \\
\text { Perception }\end{array}$ & $\begin{array}{l}\text { Grade physical } \\
\text { stress }\end{array}$ \\
\hline $4^{\circ} \mathrm{C}$ & Very cold & $\begin{array}{l}\text { Extreme cold } \\
\text { street }\end{array}$ \\
\hline $8^{\circ} \mathrm{C}$ & Cold & $\begin{array}{l}\text { Strong cold } \\
\text { stress }\end{array}$ \\
\hline $13^{\circ} \mathrm{C}$ & Cool & $\begin{array}{l}\text { Moderate cold } \\
\text { stress }\end{array}$ \\
\hline $18^{\circ} \mathrm{C}$ & Slightly cool & Slight cold stress \\
\hline $23^{\circ} \mathrm{C}$ & Comfortable & $\begin{array}{l}\text { No thermal } \\
\text { stress }\end{array}$ \\
\hline $29^{\circ} \mathrm{C}$ & Slightly warm & Slight heat stress \\
\hline $35^{\circ} \mathrm{C}$ & Warm & $\begin{array}{l}\text { Moderate heat } \\
\text { stress }\end{array}$ \\
\hline $41^{\circ} \mathrm{C}$ & $\begin{array}{l}\text { Hot } \\
\text { Very hot }\end{array}$ & $\begin{array}{l}\text { Strong heat } \\
\text { stress } \\
\text { Extreme heat } \\
\text { stress }\end{array}$ \\
\hline
\end{tabular}

PMV assesses the mean thermal perception of a group of persons in the environment [21]. The Predicted Mean Vote (PMV) considers the index to evaluate the outdoor thermal comfort that is based on the parameters of the heat balance and the perceived temperature (Table II).

\begin{tabular}{ll}
\multicolumn{2}{c}{ TABLE II: PMV INDEX [24] } \\
\hline \hline PMV & Value \\
\hline Cold & -3 \\
Cool & -2 \\
Slightly Cool & -1 \\
Neutral & 0 \\
Slightly Warm & +1 \\
Warm & +2 \\
Hot & +3 \\
& \\
\hline \hline
\end{tabular}

In contrast, Salata et al., indicated that the magnitude of the multiple reflections inside the structures could decrease the index (PMV) about 0.5 units, because of the presences of the lawn, trees and shrubs in the urban area [25].

\section{Methodology}

\section{A. Selected Study Area}

Baghdad, the capital of Iraq, is located in the central part of the country on both sides of Tigris River. It lies on latitude 43 East and longitude 34 North. The climate of the Baghdad region is defined as a semiarid, subtropical and continental, with dry, hot in summer, and cool winters. The recorded maximum temperature was $50{ }^{\circ} \mathrm{C}$ in the summer of 2010, which considers the hottest days in summer in the hottest year in Iraq [26]. The area of Baghdad covers $4555 \mathrm{Km}^{2}$, which represented $1.047 \%$ from the total area of Iraq. The population density of Baghdad city reaches to 5233 (prs) $/ \mathrm{Km}^{2}$. The selected area is Haifa Street which contains nine buildings; the height of the buildings is $60 \mathrm{~m}$, distances between the buildings are $30 \mathrm{~m}$, and some places are $35 \mathrm{~m}$. Haifa Street is one of the famous and vitality streets in Baghdad in the Karkh district. The chosen area is $48750 \mathrm{~m}^{2}$ as shown in Figs. 4 and 5.

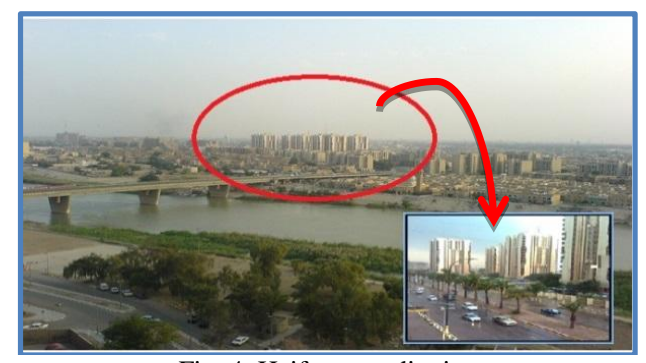

Fig. 4. Haifa street district.

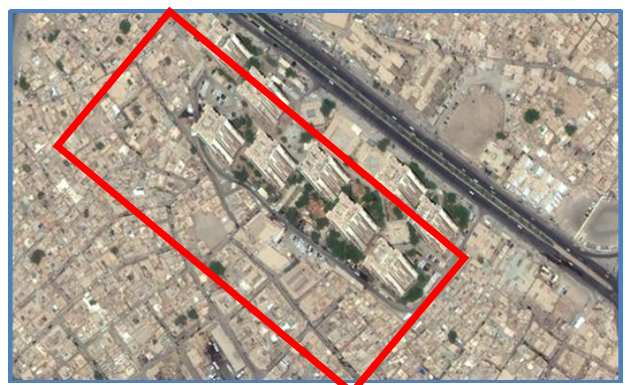

Fig. 5. 3D of satellite image ror haifa street district. [http://www.flashearth.com]

\section{B. Microscale Numerical Modelling ENVI-met}

ENVI-met is software that can simulate microscale interactions between urban surfaces, vegetation, and the atmosphere. ENVI-met allows to analyze the effects of small-scale changes in urban design (trees, backyard greening, new building) on microclimate under different mesoscale conditions. [27]. ENVI-met (version 4.0) allows to forcing input data to verify the diurnal variation of the atmospheric boundary conditions and the incoming radiation[28].The dependability of using ENVI-met for simulating the thermal performance of outdoor spaces proved in many studies. These studies denoted that the data measured or observed at local meteorological stations appeared an agreement with the simulated air temperature [29]. Monam and Ruckert [30] confirmed that according to many researches [31]-[33] ENVI-met results can be considered as precise and reliable.

ENVI-met is designed to simulate the surface-plant-air interactions in urban environments.

\section{Input Data for the Model}

The weather data used to initiate the simulation models were provided by the Iraqi Meteorological Organization and Seismology. The microclimates characteristics are representing the air temperature and relative humidity of the hottest summer day conditions in Baghdad city have been used. Therefore, the hourly meteorological data on the 12th of July 2010 [26], were considered as the hottest day of the regional weather conditions that affect on Baghdad urban area in summer.The basic meteorology settings for the initial conditions was $5 \mathrm{~m} / \mathrm{s}$ for wind speed and $315 \mathrm{deg}$. for wind direction. The simple forcing for air temperature and relative humidity are used along one day period, which explains that the minimum air temperature was $35^{\circ} \mathrm{C}$ at 6 am and maximum air temperature was $50{ }^{\circ} \mathrm{C}$ at $4 \mathrm{pm}$. The minimum relative humidity at $4 \mathrm{pm}$ was $24 \%$, the maximum relative humidity at 7 am was $36 \%$. The total simulation time is 24 hours. The modelled area has the following dimensions: $(325 \times 150) \mathrm{m}^{2}$. The model area has been rendered with grid size $x=130, y=60$ and $z=20$, this grid 
size is represented in a grid cell, the size of the grid cell is: $\mathrm{dx}=2.5 \mathrm{~m}, \mathrm{dy}=2.5 \mathrm{~m}$ and $\mathrm{dz}=5 \mathrm{~m}$. The model has been rotated of $57^{\circ}$ according to the location of the buildings to the main North direction.

\section{The Model Configuration}

The comparative investigation simulation work focuses on analysing the human thermal comfort at the pedestrian level in four scenarios characterized by different greenery strategies, such as grass, various types of trees. Also, two different shadow patterns have been created by assuming the pergolas around the buildings. Other proposals for shading are created for the pedestrians which trees on the both sides surrounding the pergolas.

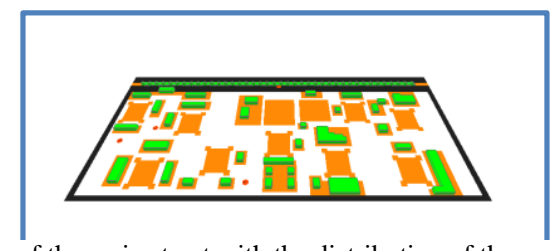

Fig. 6. Map of the main street with the distribution of the vegetation for Base model simulated by ENVI-met.

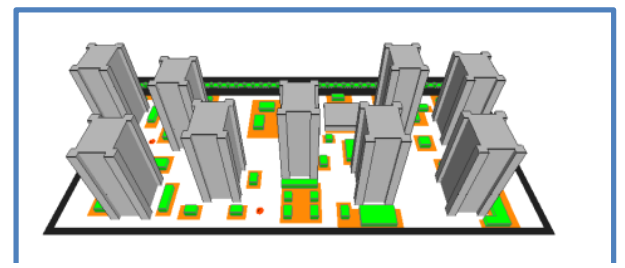

Fig. 7. Perspective view of the Base model simulated by ENVI-met

\section{E. Scenarios}

For evaluating the impact of the shadings pattern and vegetation on the outdoor thermal pedestrian comfort, four different scenarios are representing the main climate strategies to mitigate Urban Heat Island effects. In addition to the base case plan, another three scenarios have been simulated, the models are:

- Base Model: base model (BM) is the case study of the urban area (Haifa Street), there are very few trees (Citrus) without vegetation in this model (Fig 6 and 7). Fig. 8 shows the 2D configuration for Base Model simulated by ENVI-met.

- Vegetation model: Grass and Trees model (GT) has been assumed around the buildings, to evaluate the effect of vegetation in the selected area. Sophora Japonica is assumed in this model with a space of grass around the urban area. (Sophora Japonica) which is rounded- headed tree with spreading branches, (4.5-9) m high. Young branches and twigs are densely shortly pubescent [34]. Fig. 9 describes 2D of Grass and Trees model that are simulated by ENVI-met.

- Shadow model (Pergolas around buildings): (PAB) this model assumed that the pergolas are imposed around the buildings with $4 \mathrm{~m}$ height. Trees are distributed around theses pergolas defined as Sophora Japonica. Fig. 10 shows 2D of Shadow model that are simulated by ENVI-met.

- Sophora Japonica around the pergolas for the Pedestrians: this model (SJP) represented the model that was proposed to acquire the thermal comfort for the pedestrians and solved the problems of the large spacing between the buildings. Fig. 11 explains the objective of this model to provide the continued shadings for the pedestrians by a grid of pergolas. Sophora Japonica trees on the both sides surround the pergolas. Fig. 12 shows the perspective view of this model simulated by ENVI-met. Figs. 13 and 14 depict the simulated model before and after trees were distributed around the pergolas for the pedestrians.

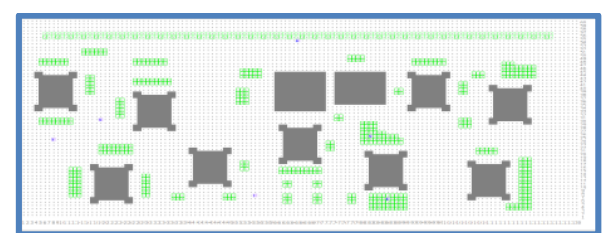

Fig. 8. 2D for Base model (BM) of Haifa Street District simulated by ENVI-met.

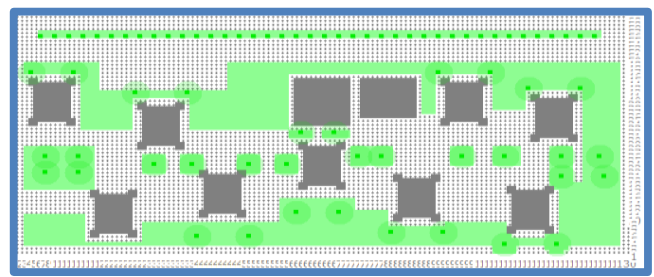

Fig. 9. 2D for Grass and Trees model (GT) of Haifa Street District simulated by ENVI-met.

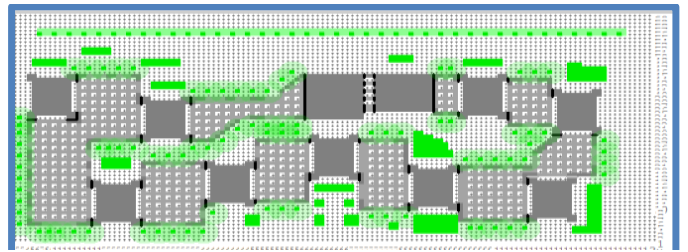

Fig. 10. 2D for the pergolas around the buildings (PAB) of Haifa Street District simulated by ENVI-met.

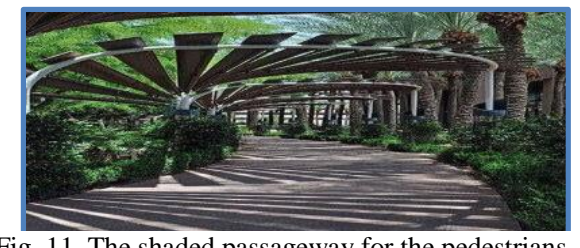

Fig. 11. The shaded passageway for the pedestrians.

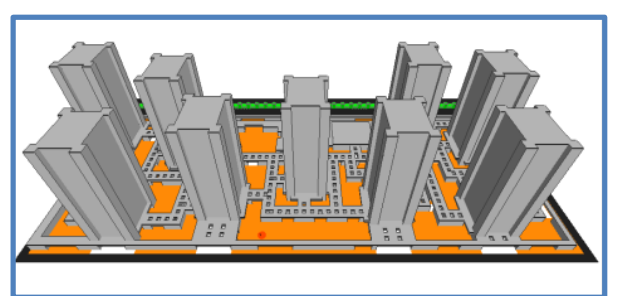

Fig. 12. Perspective view for the model the pergolas for the Pedestrians before Sophora Japonica trees were distributed around the pergolas simulated by ENVI-met.

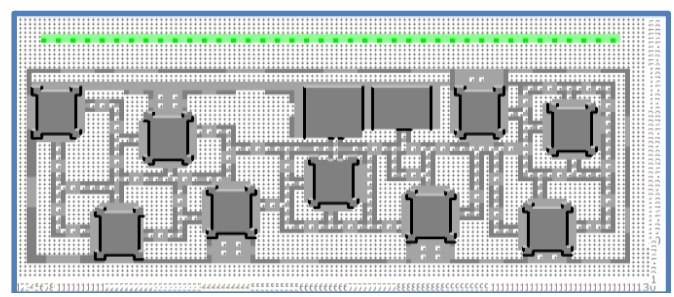

Fig. 13. 2D for the model the pergolas for the Pedestrians before Sophora Japonica trees were distributed around the pergolas simulated by ENVImet. 


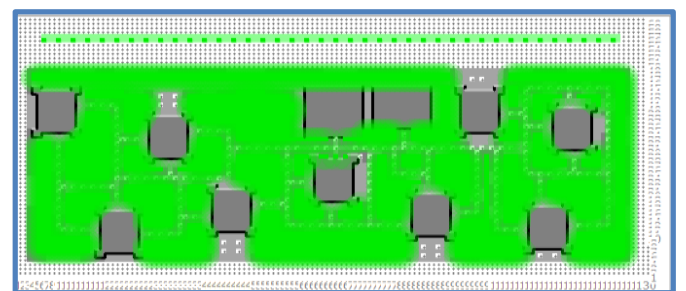

Fig. 14. 2D for the model the pergolas for the Pedestrians after Sophora Japonica trees were distributed around the pergolas (SJP) simulated by ENVI-met.

\section{ANALYSIS OF THE RESULTS OF THE OUTDOOR THERMAL COMFORT}

We analyze the estimated thermal comfort conditions along a proposed pedestrian path linking all the buildings at noon. PET and PMV are measured to evaluate the outdoor thermal comfort for pedestrians for the selected urban area. A scenario of the walkway that is connected with the buildings in the urban area is simulated to illustrate the objective of the transitional thermal conditions of the pedestrians. The path (A-B) observed in Fig. 15 is about $120 \mathrm{~m}$ long.

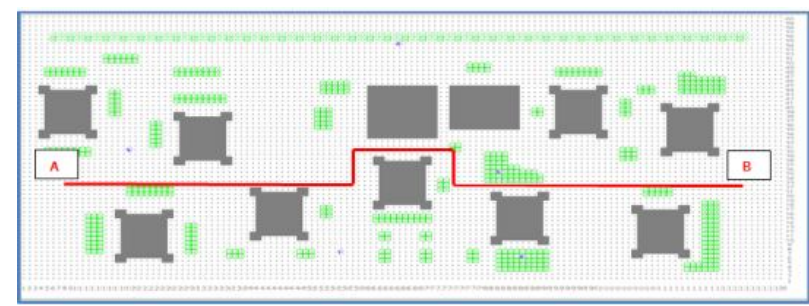

Fig. 15. The path (A-B) way of the pedestrian in the urban area.

The model (SJP) contributed to minimizing the air temperature along the pedestrians range from 1.83 to $2.42{ }^{\circ} \mathrm{C}$ as shown in Fig. 16. The pergolas reduce the effect of temperature in the urban area because of the decrease in the sky view factor, and the effect of sun radiation. Also, trees that are surrounded by the pergolas obstructed the passage of long-wave radiation between the buildings, the ground surfaces and the sky. This could be explained by the effect of sky view factor on air temperature. Higher sky view factor in the base model (BM) leads to higher air temperature in the urban area because the increasing of sky view factor potentially leads to the increase of the open space and the amount of long wave radiation absorbed by the ground surfaces and buildings façades and roofs. A slight decrease in air temperature is observed for grass and trees model (GT); this means that the trees covers along the walkways of the pedestrians did not contribute to reducing the temperature at noon, because of the high absorption of long-wave radiation from the ground surfaces. The big space between buildings plays a significant role in absorption and storage heat on the ground. Results for (PAB) model show that this solution not contributes to providing enough cover for reducing sunlight and heat absorption by the surfaces: the decrease in the temperature is too insignificant. Although the modification of grass and trees model (GT) and pergolas around the buildings (PAB) could consider a good solution to mitigate the high temperatures, in this case, We contend with the difficulties in the design of the Base model (BM) for the urban area. The first one is the high rise buildings. Second, asymmetric distribution for the buildings which leads to big open space between the buildings, this means the shading from the tall buildings to each other is lost. The long distances between the buildings would create a big space of surface ground could absorb heat and keep it along daytime. The results that are obtained for mean radiant temperature indicated that the minimum values of the mean radiant temperature could be observed in the (SJP) model as shown in Fig. 17, because of the effect of the shadings that are obtained from the existence of the pergolas along the path (A-B) of the pedestrians and the effect of the shadow from the trees. The maximum decrease in values of mean radiant temperature reaches to $35^{\circ} \mathrm{C}$ on the path (A-B) that are recorded in the Sophora Japonica around pergolas of the pedestrians (SJP). The reason is attributed to the presence of the shading and the decreases for emitting of the long wave radiation from the surfaces of buildings and the grounds. The surface temperature of urban facades is the primary factor that could contribute to reducing thermal comfort. The results of grass and trees (GT) model are almost convergent to the Base model due to lack of shadings which enhanced to decrease the values of mean radiant temperatures. Shadows, which are obtained from (PAB) model was not enough on improving the results of mean radiant temperature comparing with the Base model results.

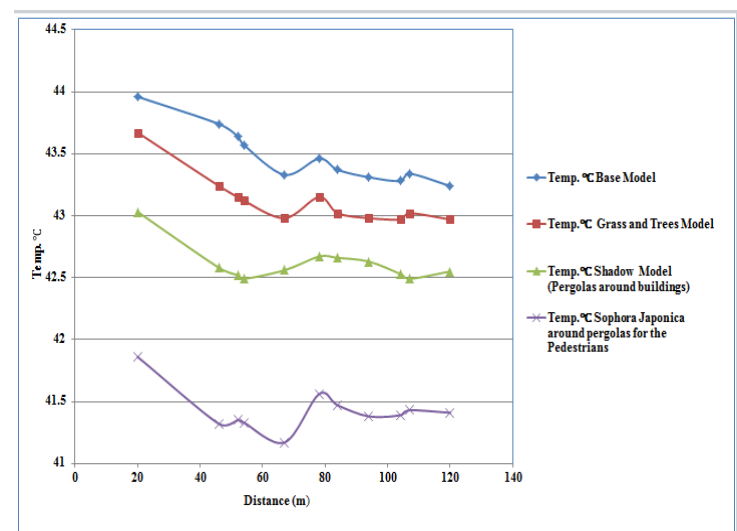

Fig. 16. Air temperature distribution at noon at level $1.5 \mathrm{~m}$ for the path (A-B) of the pedestrians.

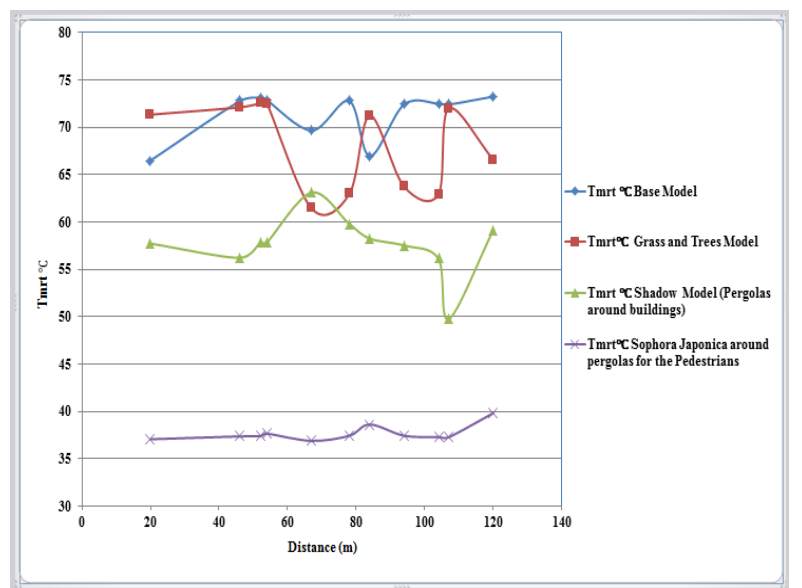

Fig. 17. Mean radiant temperature at noon at level $1.5 \mathrm{~m}$ above the ground for the path (A-B) of the pedestrians.

Fig. 18 shows that the specific humidity values have the highest level for Sophora Japonica around the pergolas of the pedestrians (SJP) model due to the presence of the large 
density of trees in the whole space of the urban area.

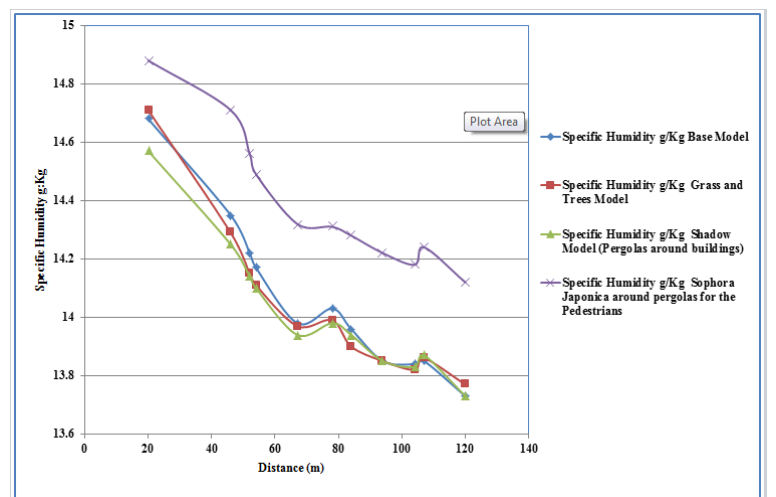

Fig. 18. Specific Humidity at noon at level $1.5 \mathrm{~m}$ above the ground for the path (A-B) of the pedestrians.

According to Figs. 19 and 20 we observed that the shading of trees could impact the human thermal comfort. The Sophora Japonica around pergolas for the pedestrians model (SJP) is the best configuration for improving the thermal comfort. We obtained a decrease in PET values from the base model reached to $10.42^{\circ} \mathrm{C}$ in the path (A-B) for the pedestrians, and 3.01 in PMV values. Correspondingly, changes in thermal comfort for PET and PMV values for other models is barely apparent because the most important factors are the presence of sufficient vegetation and smaller values sky view factor.

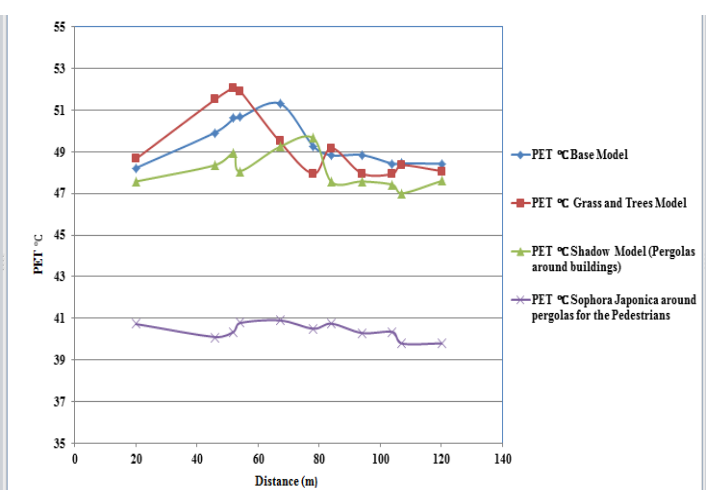

Fig. 19. PET at noon at level $1.5 \mathrm{~m}$ above the ground for the path (A-B) of the pedestrians.

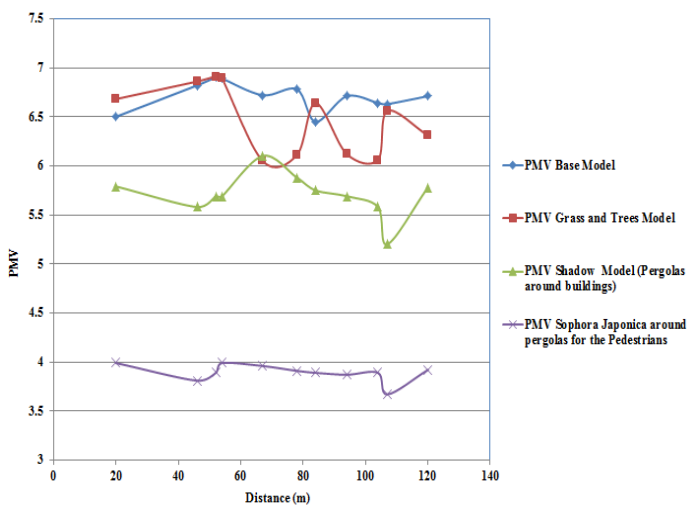

Fig. 20. PMV at noon at level $1.5 \mathrm{~m}$ above the ground for the path (A-B) of the pedestrians.

The suggestion of the greenery strategies patterns models could take in consideration of the design developments of the urban area. Although the plants need some water to grow and live in such an arid climate, this drawback will be easy to solve because the district is near from Tiger River.
We need to take into account the park and garden maintenance because of the deciduous leaves of the trees. The pesticides could overcome insect problem.

\section{CONCLUSIONS}

The present study is conducted to assess the perception of the thermal comfort for the two indices PMV and PMT. Simulation works are performed on the hottest day in summer [26] so, the results revealed a decrease in temperature of approximately $2.4{ }^{\circ} \mathrm{C}$ and $10.4{ }^{\circ} \mathrm{C}$ in PET index for the (SJP) model and a reduce in PMV to 3. The maximum decrease in values of mean radiant temperature reaches $35^{\circ} \mathrm{C}$. We confront the difficulties in the western design in an arid climate area without taking into consideration the human thermal comfort for pedestrians especially in a hot season in summer. High rise buildings, asymmetrical canyons, the big spacing between buildings, lack of vegetation and the loss of shading feature play a significant role. The final outcomes of the study could lead to urban planning recommendations for municipalities and urban planners.

\section{REFERENCES}

[1] T. Rajabi and B. Abu-Hijleh, "The study of vegetation effects on reduction of urban heat Island in Dubai," World SB 4 Barcelona October 28/ 30th 2014.

[2] P. Shahmohamadia, A. I. Che-Ania, I. K. N. Etessamb, A. N. Mauludc, and M. Tawila, "Healthy environment: The need to mitigate urban heat Island effects on human health," in Proc. the 2nd International Building Control Conference 2011, Procedia Engineering, vol. 20, 2011, pp. 61-70.

[3] Y. Charabi and A. Bakhit, "Assessment of the canopy urban heat Island of a coastal arid tropical city: The case of muscat, Oman," Atmospheric Research, vol. 101, pp. 215-227, 2011.

[4] H. Radhi, F. Fikry, and S. Sharples, "Impacts of Urbanisation on the thermal behaviour of new built up environments: A scope study of the urban heat Island in Bahrain," Landscape and Urban Planning, vol. 113, pp. 47-61, 2013.

[5] M. Fahmy and S. Sharples, "On the development of an urban passive thermal comfort system in Cairo, Egypt," Building and Environment, vol. 44, pp. 1907-1916, 2009.

[6] L. Shashua-Bar and M. E. Hoffman, "Vegetation as a climatic component in the design of an urban street an empirical model for predicting the cooling effect of urban green areas with trees," Energy and Buildings, vol. 31, pp. 221-235, 2000.

[7] K. Fabbri, Indoor Thermal Comfort Perception, Springer International Publishing, Switzerland, pp. 978-319-18650-4, 2015.

[8] A. Auliciem and S. V. Szokolay, "Passive and low energy architecture international design tools and techniques," PLEA: Passive and Low Energy Architecture International in Association with Department of Architecture, The University of Queensland, 2007.

[9] M. Taeghani, M. Tenpierik, S. Kurvers, and A. Dobbelsteen, "A review into thermal comfort in buildings," Renewable and Sustainable Energy Reviews, 26, pp. 201-215, 2013.

[10] K. Fabbri, Indoor Thermal Comfort Perception, Springer, 2015.

[11] A. Standard, "Thermal environmental conditions for human occupancy," American National Standard, 2012.

[12] E. Jamei and P. Rajagopalan, "Urban growth and pedestrian thermal comfort," in Proc. $49^{\text {th }}$ International Conference of the Architecture Science Association, the Architecture Association and the University of Melbourne, pp. 907-918, 2015.

[13] E. Landsberg, The Urban Climate, Maryland Academic Press, 1981.

[14] Y. Wang and H. Akbari, "Effect of sky view factor on outdoor temperature and comfort in montreal," Environmental Engineering Science, vol. 31, no. 6, 2014.

[15] S. Peng, S. Piao, and P. Ciais, "Surface urban heat Island across 419 global big cities," Environmental Science Technology, vol. 46, pp. 696, 2011. 
[16] S. Thorsson, J. Rocklöv, J. Konarska, F. Lindberg, B. Holmer, B. Dousset, and D. Rayner, "Mean radiant temperature a predictor of heat related mortality," Urban Climate, vol. 10, pp. 332-345, 2014.

[17] A. Matzarakis, F. Rutz, and H. Mayer, "Modelling radiation fluxes in simple and complex environment: Basis of the ray man model," International Journal Biometeorology, vol. 54, pp. 131-139, 2010.

[18] L. Kutscher, R. Burkhardt, and S. Campe, "Microclimatic analysis of Arnhem. future cities," Urban Networks to Face Climate Change. Department of Environmental Meteorology Institute for architecture, Germany, January, 2012.

[19] F. Ali-Toudert and H. Mayer, "Numerical study on the effects of aspect ratio and orientation of an urban street canyon on outdoor thermal comfort in hot and dry climate," Building and Environmental, vol. 41, pp. 94-108, 2006.

[20] A. Rashida, "Optimizing the effect of vegetation for pedestrian thermal comfort and urban heat Island mitigation in a hot arid urban environment," Ph.D. A Dissertation Presented in Partial Fulfilment of the Requirement for the degree Doctor of Philosophy, Arizona State University, May 2014

[21] H. Perrineau, "Development of a tool based on the thermal dynamic simulation software TRNSYS which runs parameters studies to assess outdoor comfort with the perceived temperature, INSA," Strasbourg. End-of-Studies Project carried out at TRANSSOLAR in Stuttgart, August 2013.

[22] N. Makaremi, E. Salleh, M. Z. Jaffar, A. Hosein, and G. Hoseini, "Thermal comfort conditions of shaded spaces in hot and humid climate of Malaysia," Building and Environmental, vol. 48, pp. 7-14, 2012.

[23] A. Matzarakis and B. Amelung, "Physiological equivalent temperature as indicator for impacts of climate change on thermal comfort of humans," Springer Science, 2008.

[24] A. Standard, "Thermal environmental conditions for human occupancy," ANSI, American Society of Heating Refrigerating and Air- Conditioning Engineering, INC, 2004.

[25] F. Salata, I. Gllasi, E. L. Vollaro, F. Bisegna, F. Nardecchia, M. Coppi, F. Gugliermetti, and A. L. Vollaro, "Evaluation of different urban microclimate mitigation strategies through a PMV analysis," Sustainability, vol. 7, pp. 9012-9030, 2015.

[26] A. F. Hassoon, "Assessment of air pollution elements concentrations in Baghdad city from periods (May-December) 2010," International Journal of Energy and Environment, vol. 6, no. 2, pp. 191-200, 2015

[27] S. Huttner, "Further development and application of the 3D microclimate simulation ENVI-met," Ph.D. Thesis, Mainz, 2012.
[28] S. Huttner and M. Bruse, "Numerical modelling of the urban climate a preview on ENVI-met 4.0," The Seventh International Conference on Urban Climate, 29 June-3 July 2009, Yokohama, Japan.

[29] A. Ghaffarianhoseini and U. Berardi, "Thermal performance characteristics of unshaded courtyards in hot and humid climates," Building and Environmental, vol. 87, pp. 154-168, 2015.

[30] A. Monam and K. Ruckert, "The dependence of outdoor thermal comfort on urban layouts," German-Iranian Research Project, 2013.

[31] F. F. Ali-Toudert, "Dependence of outdoor thermal comfort on street design in hot and dry climate," Ph.D. Thesis, Freiburg, Germany, November, 2005

[32] I. Ozkeresteci, K. Crewe, and M. Bruse, "Use and evaluation of the envi-met model for environmental design and planning: An experiment on linear parks," in Proc. the 21st International Conference (ICC), Durban, South Africa, pp. 10-16, 2003.

[33] E. Lahme and M. Brus, "Microclimatic effects of a small urban park in densely built-up areas: Measurements and model simulations," in Proc. the European Commission in the 5th Framework Program Under the Contract EVK4-CT-2000-00041, 2002.

[34] C. C. Townsend and E. Guest, "Flora of IRAQ" ministry of agriculture and agrarian reform, Iraq, 1974.

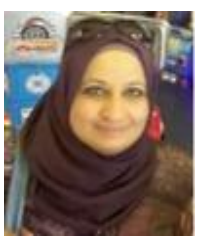

Suaad J. Ridha was born in Baghdad, in 1972. She received her Ph.D from University of Toulouse, INSA. 2014, a M.Sc in civil engineering department construction projects management in 2000, Iraq. She received her B. Sc civil engineering from AlMustansiriya University in 1995 , Iraq. She is a lecturer in the Department of Civil Engineering from 2001 to 2012. Responsible of the "Official Unit of Post-Graduate Studies" in the Deanery of the Faculty of Engineering / AlMustansiriya University. 2009-2010. She is a director of the "Unit of Continuing Education," Faculty of Engineering/ Al-Mustansiriya University 2011-2012. 